\title{
Design of Project Teaching System for Information Management and Information System under the Perspective of OBE
}

\author{
Yanxia Lu ${ }^{1, a^{*}}$, Jingshu Wang ${ }^{1, b}$ and Di Wu ${ }^{1, c}$ \\ ${ }^{1}$ Dalian Neusoft University of Information, Department of Information Management, Dalian, China \\ aluyanxia@neusoft.edu.cn, bwangjingshu@neusoft.edu.cn, cwudi@neusoft.edu.cn \\ * The Corresponding Author
}

Keywords: Information management and information system; OBE perspective; personnel training; project teaching

\begin{abstract}
Based on the goal of training innovative and applied talents, this paper introduces the concept of OBE education in engineering education. Through a comprehensive survey of stakeholders, the objectives of professional training and graduation requirements are clarified based on the goal of training information professionals in information management and information system. By constructing the professional ability system and combing the field of professional knowledge, a teaching system based on OBE is designed.
\end{abstract}

\section{Introduction}

With the continuous development of China's economy and its rising international status, talent training in colleges and universities is no longer focused solely on the process. More attention is paid to the effect of personnel training. However, at present, there are still many problems such as the unclear training objectives, the unreasonable design of the course system structure, the imperfect system of ability, the rough teaching design, the redundant course content, the dull classroom, the single examination form, etc., Teaching objectives and expectations there is deviation, talent training effect is difficult to reach.

Information management and information systems is a combination of management and technology applied interdisciplinary, responsible for the burden of enterprise information personnel training [1]. Traditional information management and information system professionals pay more attention to one-way input of knowledge, but neglect the learning effect of students, which leads to the passive status of teaching, learning, practicing and using phase separation [2]. However, with the advent of new technologies such as cloud computing, Internet of things and big data, the requirements of enterprise management and business are gradually deepening, and the quality requirements for the training of informatization personnel are also gradually raised [3]. The traditional mode of personnel training is no longer completely. To adapt to the needs of the community for enterprise information personnel training, college education and information system of information management and education reform is imperative.

Based on the TOPCARES-CDIO and OBE education philosophy of our university, based on the cooperation between school and enterprises, and with the cooperation of industry and education, this paper aims to improve students' engineering practice ability and professional core competencies, concludes the characteristics and optimization projects of information management and information system specialty teaching system, to build an integrated application of personnel training mode, so as to effectively enhance the overall quality of students and practical ability.

\section{Research Status of OBE-based Undergraduate Professional Education Reform}

American educator Spady first proposed Outcome-Based Education(OBE)-based education philosophy based on outcomes of student learning in The Output-Based Education Model: Disputes and Answers. At present, OBE has been applied in many colleges and universities in professional construction and curriculum reform and achieved some results.

In terms of professional construction and teaching reform, Gu Peihua [4] and Feng Quan [5] systematically expounded the concept, theoretical basis and characteristics of OBE, and discussed in 
depth the practical significance of OBE's educational model for innovative and applied talents. He Zhiyuan [6] reversely designed the electrical engineering talent training program and curriculum system, and realized the continuous improvement of personnel training through the three cycles of in-class, inside-school and outside-school, and improved the quality of personnel training. Based on the concept of OBE, Wang Qiang [7] takes logistics engineering as the research object and explores the application-oriented undergraduate training mode, training objectives and curriculum system. Xing Hui [8] explored the whole process of professional teaching reform from the aspects of training objectives, curriculum system, teaching mode, teaching evaluation and teaching quality with the exhibition of turbine engineering in Dalian Maritime University. Xia Yu [9] explored the reform of education and teaching of digital media major, constructed the curriculum system and evaluation mechanism based on the concept of $\mathrm{OBE}$, and put forward the important role of industry college and effectively realized the in-depth integration of school and enterprise.

In terms of project teaching, Zeng Yi [10] took the example of Xingjian University of Arts and Sciences in Guangxi University as an example, and put forward the goal, content and measures for the practical teaching of school-industry cooperation and achieved initial results through practice tests. Meng Xiaolu [11] to Fuzhou University of Foreign Studies, for example, to build a letter of professional practice teaching system, based on the basic module, application module and innovation to improve the module to cultivate foreign trade enterprises, information technology personnel.

It can be seen that there are many applied institutes in our country to implement OBE education and teaching reform and achieved initial success. However, for the interdisciplinary such as information management and information system, there are many different professional settings in colleges and universities, scattered in the business administration, management, computer science and other departments, so there are different professional background, training objectives Not clear, the practice system is not clear, the enterprise interaction is not deep and so on a number of issues. The timely introduction of advanced concepts of OBE education and the reform of the teaching system of existing personnel training programs are problems urgently needed by the major.

\section{Design of OBE-based Project Teaching System}

Firstly, it conducts research on stakeholders through network research, questionnaires, business visits, expert interviews and professional seminars, and obtains social needs of enterprises, parents, students, interns, graduates and other social needs, and further clarifies the characteristics based on ERP Of the personnel training model, and improve the training objectives; and then refer to the Ministry of Education and Teaching Steering Committee on information management and information systems professional guidance and national and international engineering education certification standards, to determine the professional graduation requirements; professional graduation requirements, based on school positioning and professional characteristics, the development of quantitative learning outcomes, and graduation requirements will be broken down one by one into the system of professional personnel training in order to achieve the goal of training personnel; Finally, through the field of knowledge, the graduation requirements of the mapping system of competencies Corresponds to the project unit, in order to achieve the integration of project design and optimization. For the project teaching system, through the class teaching, extra-curricular practice, enterprise internship three links to achieve the integration of engineering practice ability. Specific as shown in Fig. 1. 


\section{Reform Practice of OBE-based Information Management and Information System Practice Teaching}

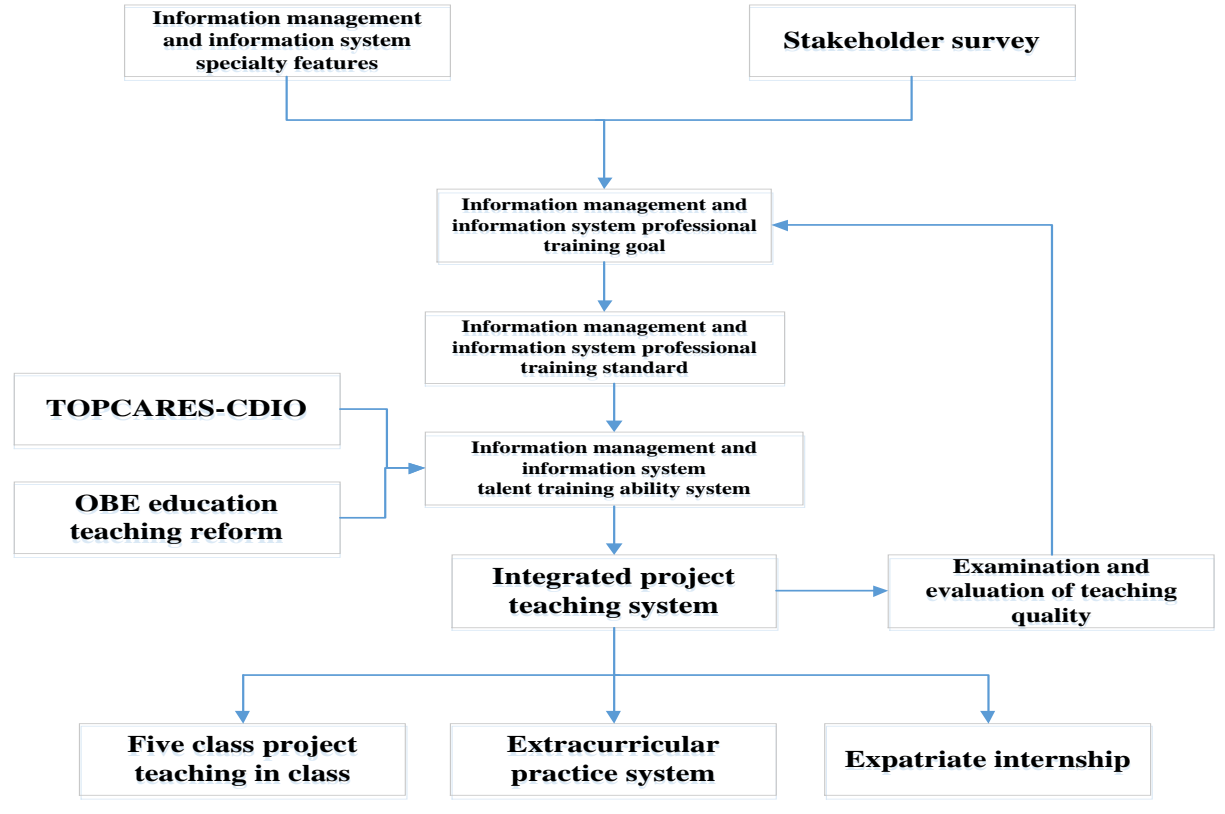

Figure 1. OBE-based integrated project teaching system design

Talent training objectives and graduation requirements. Based on our innovative and applied personnel training characteristics and many years of professional practical experience, with the recent two years of big data, cloud computing and other emerging technologies, our school information management and information systems professionals have established a business data analysis and processing Related technology and ERP as the core of the integration of personnel training system. Through continuous tracking of graduates 'employment data in the past 4 years, the scope of graduates' employment can be obtained as shown in Fig. 2. The survey found that most of the information management and information system students in our school are employed in industrial and commercial enterprises and IT companies.

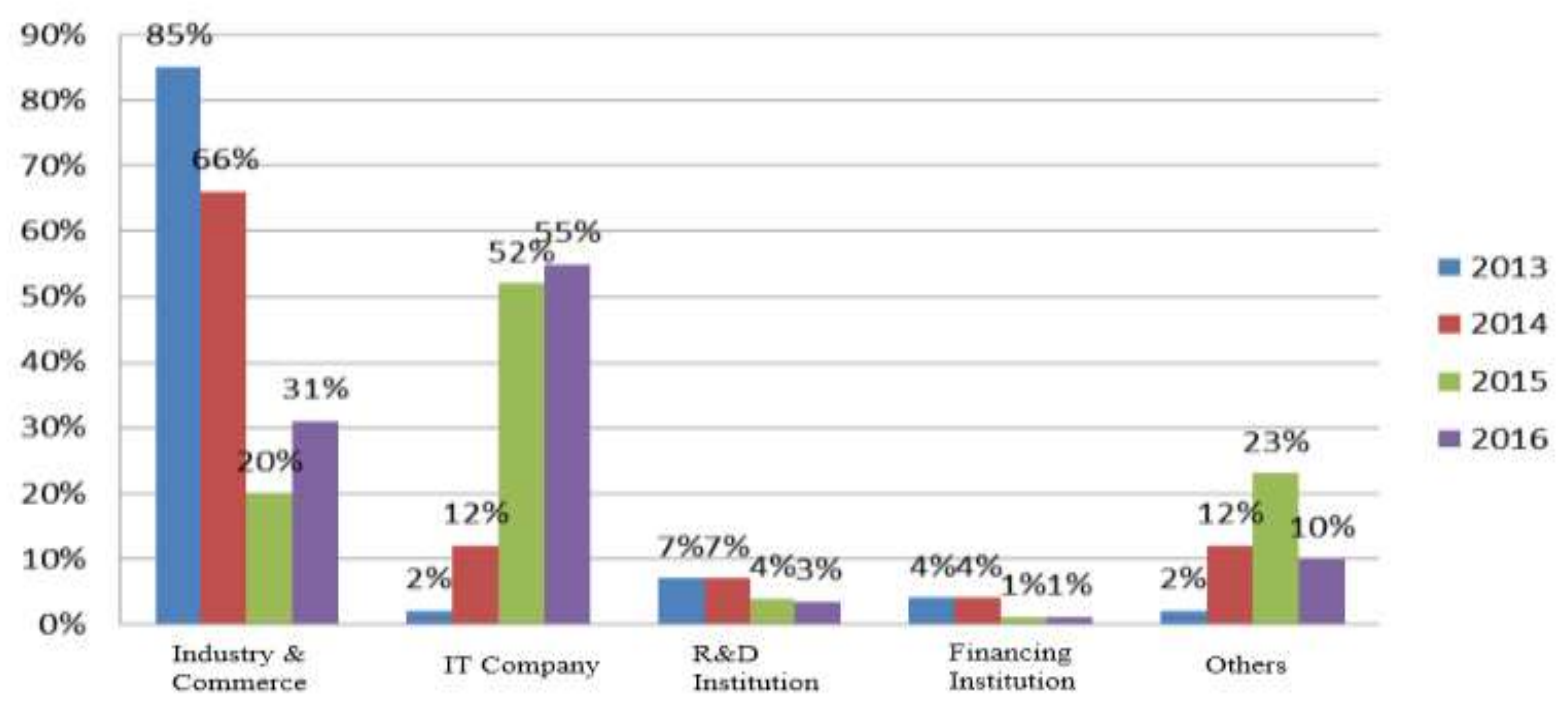

Figure 2. Graduate employment area

With the gradual deepening of the OBE reform, the information management and information system specialty investigated 64 cooperation bases for schools and enterprises. At the same time, 153 enterprise informationization companies were surveyed through the Internet to obtain the capacity 
requirements of enterprises for students and graduates. A level, 32 two, 59 three level indicators. At the same time, with the comprehensive social research among students, graduates, parents and college experts, it is determined that the major of information management and information system in our school should aim at cultivating ERP application engineers. Five years after graduation, students should master modern enterprise management and information technology expertise, have strong information system application capabilities, and engage in high-quality and application-oriented ERP applications and development in such fields as industrial and commercial enterprises, IT companies, government agencies and financial institutions Specialized personnel. OBE-based educational philosophy focus on learning outcomes, in order to better achieve the objectives of professional training and effective achievement of many professional discussions, from the professional knowledge, professional skills, professional qualifications in three areas to determine the professional graduation requirements and ability system. Some of the contents and requirements shown in Table 1.

Table 1 Part of the graduation requirements and ability system

\begin{tabular}{|c|c|}
\hline Graduation requirements & Professional training ability system \\
\hline \multirow{5}{*}{$\begin{array}{l}\text { Have the ability to put forward problems, analyze and } \\
\text { solve problems. }\end{array}$} & System thinking \\
\hline & Critical thinking \\
\hline & Innovation ability \\
\hline & Reasoning and problem solving skills \\
\hline & Experiment and discover knowledge \\
\hline \multirow{3}{*}{$\begin{array}{l}\text { Good communication and expression ability, with a } \\
\text { certain international vision and foreign language } \\
\text { application ability. }\end{array}$} & Humanities and social science knowledge \\
\hline & Experiment and discover knowledge \\
\hline & Use foreign language skills \\
\hline $\begin{array}{l}\text { Have a certain team ability to work in a } \\
\text { multidisciplinary team. }\end{array}$ & Teamwork \\
\hline \multirow{2}{*}{$\begin{array}{l}\text { Have the management ability of time and resources, } \\
\text { and have a certain ability of relearning. }\end{array}$} & Time and resource management capabilities \\
\hline & Lifelong learning ability \\
\hline
\end{tabular}

Design of project teaching system in class. The information management and information system major is an interdisciplinary course integrating information technology and management technology. Based on the characteristics of information management and information system in our school and the real project and case resources of our university, Management and technology integration of five integrated project system. details as follows:

Level 1 project: Involves the overall professional training objectives, refers to the professional core curriculum and ability requirements of the integrated project. Focus on cultivating students' professional core competence. Such as professional guidance project, comprehensive training project, graduation project.

Level 2 project: This is a course group that is based on a number of courses and includes a set of core competencies that are relevant to the course. Organizing the associated course knowledge organically enables students to recognize the organic and associated knowledge clusters among courses rather than isolated knowledge points, and guide students to apply the knowledge of the course group practice, the combination of knowledge and ability. Such as: business operations simulation practice, enterprise accounting practice, ERP project implementation and so on.

Level 3 project: Single-course courses to enhance the ability to achieve the goal of the curriculum, such as database theory and application of curriculum design small database design projects, enterprise resource planning curriculum designed for small business ERP basic applications.

Level 4 project: A unit project designed to reinforce the competency objectives of a course based on the ability of more than 2 modules (modules) in a course. For example, enterprise resource planning course covers five level 4 projects such as financial management, purchasing management, production management, inventory management and sales management. 
Level 5 project: A unit project designed to enhance competence in one unit (module) based on a course.

This article builds the information management and information system specialized course integration project teaching system as shown in Fig. 3.

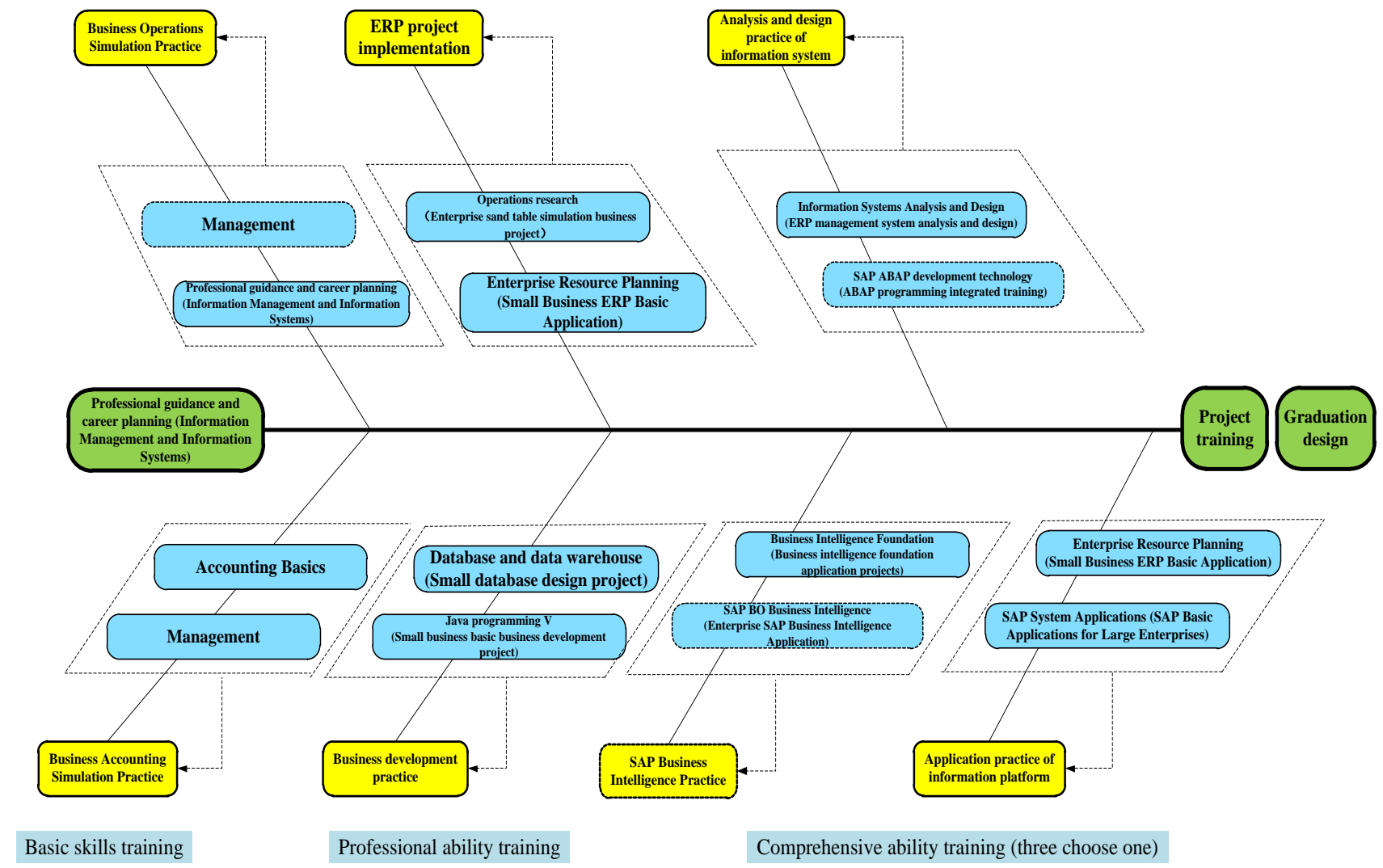

Figure 3. Integrated project teaching system

Design of project teaching system out of class. According to the demand of the enterprise for cultivating students' practical ability in information management and information system specialty, this paper designs three kinds of special topics in the extra-curricular project, such as management forefront class, professional technology class and enterprise innovation and entrepreneurship application class. The topics can be derived from one or more courses of knowledge expansion, it can also be a new theory, new methods, new tools or new products introduced with the development of technology, through various topics and theories, practice courses Organic integration of the system to achieve the extension of students 'professional knowledge and skills, and promote students' open-minded and innovative awareness training.

In extracurricular activities, teachers can enhance students' comprehensive practical ability through quality education programs, associations, SOVOs, subject competitions, corporate internships and assignments. Relying on the school community, SOVO and many practice bases outside the school, in the first year through professional quality education programs, professional community practice, social practice, career planning competition for college students to achieve a basic understanding of professional and innovative spirit and awareness training; Second, enhance students 'professional practical skills and basic innovative abilities through enterprise sand table competition, service outsourcing competition, mathematical modeling competition and "create a youth" competition; enhance students' professional practice in the third year through university student innovation projects and SOVO real projects And innovative ability; in the fourth year through internship and assignment in cooperation between school-enterprise cooperation, to achieve the students' comprehensive practice and ability of innovation.

Information management and information system integration of extra-curricular teaching system design shown in Fig. 4. 


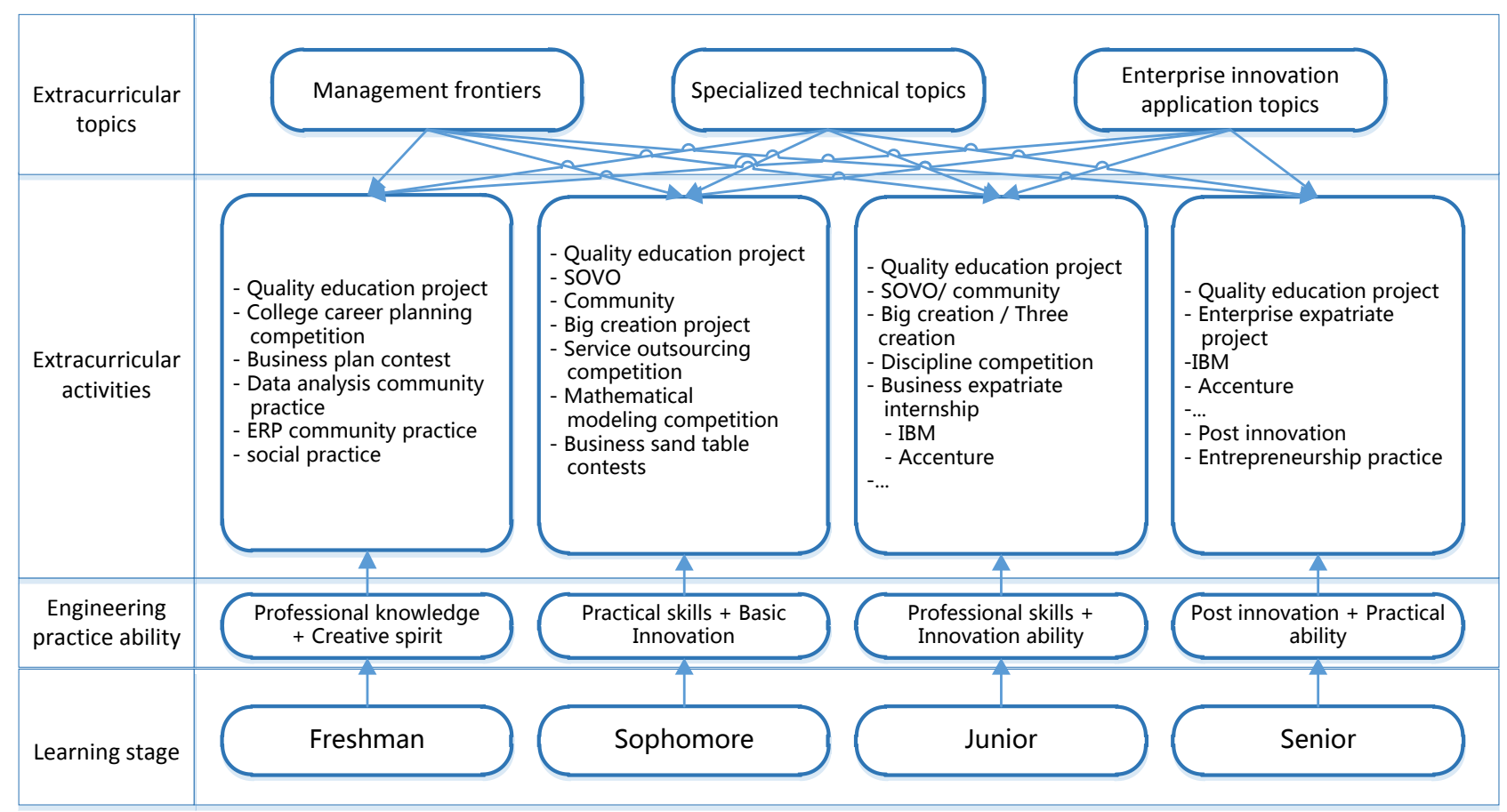

Figure 4. Integration of extra-curricular teaching system design

\section{Summary}

OBE-based professional reform is an effective way to implement innovative teaching reform in applied colleges and universities. This paper elaborates on the basis of research background, research status, project teaching design ideas and professional practice in detail based on OBE of information management and information system major The project teaching system design provides some reference for the cultivation of engineering practice ability of similar professionals in colleges and universities in our country.

\section{References}

[1] Lu Yanxia, Wu Di, Zhang Xiaoyan. ERP SAP course group based on innovation ability based information management class construction [J]. computer education. 2016 (11):49-53.

[2] Jiang Hua. Construction of information management and information system applied talents training system [J]. computer education. 2016 (3):25-28

[3] Lu Yanxia, Huang Chuanlin, Liang Yi Da. Under the big data SAP based enterprise information training curriculum system for enterprise information construction [J]. computer education. 2015 (14): 19-22.

[4] Gu Peihua, Hu Wenlong, Lin Peng, et al. Engineering education mode based on learning output (OBE) -- Practice and exploration of Shantou University [J]. higher engineering education research. 2014 (1): 27-37.

[5] Feng Quan. Research on the training of Applied Talents under OBE education model [J]. Journal of Anhui Engineering University. 2016 (3): 81-85.

[6] He Zhiyuan, Zheng Yuzhen, Zhou Kening. Research on the training of electrical engineering talents based on OBE concept and FH model [J]. Journal of Zhejiang University of Science and Technology. 2015 (5): 355-359.

[7] Wang Qiang, Li Wen, Li Rong, et al. The training mode of Applied Logistics Engineering Talents Based on OBE education concept. Journal of [J]. Heilongjiang Academy of Engineering, 2017 (2): 77-80. 
[8] Xing Hui, Bi Pengjie, Liu Qinan. Based on results oriented Education (OBE) teaching reform of marine engineering major [J]. marine education research. 2017 (1): 49-55.

[9] Xia Yu, Gong Sheng Rong. Based on the OBE concept of digital media professional applied talent training model [J]. computer education. 2017 (4): 82-86.

[10]Zeng Yi. The exploration and practice of information management and information system of school enterprise cooperation practice teaching -- Taking Guangxi University as an example Chinese Xingiian College of Arts and Sciences [J]. new communications, 2017,19 (06): 137-138.

[11] Meng Xiaolu. By the foreign trade enterprise information oriented construction of personnel information management practice teaching system [J]. Journal of Beijing City University, 2017 (04): 58-62. 